\title{
Binge eating symptomatology in overweight and obese patients with schizophrenia: a case control study Yasser Khazaal ${ }^{* 1}$, Emmanuelle Frésard ${ }^{1}$, François Borgeat ${ }^{1}$ and Daniele Zullino ${ }^{2}$
}

\author{
Address: ${ }^{1}$ Department of Psychiatry, University Hospital of Vaud, Echallens 9, 1004 Lausanne, Switzerland and ${ }^{2}$ University Hospitals of Geneva, \\ Division of Substance Abuse, Rue Verte 2, 1205 Geneva, Switzerland \\ Email: Yasser Khazaal* - yasser.khazaal@chuv.ch; Emmanuelle Frésard - emmanuelle.fresard@chuv.ch; \\ François Borgeat - françois.borgeat@chuv.ch; Daniele Zullino - daniele.zullino@hcuge.ch \\ * Corresponding author
}

Published: 12 September 2006

Annals of General Psychiatry 2006, 5:15 doi:10.1186/1744-859X-5-15
Received: 30 January 2006

Accepted: 12 September 2006

This article is available from: http://www.annals-general-psychiatry.com/content/5/I/I5

(c) 2006 Khazaal et al; licensee BioMed Central Ltd.

This is an Open Access article distributed under the terms of the Creative Commons Attribution License (http://creativecommons.org/licenses/by/2.0), which permits unrestricted use, distribution, and reproduction in any medium, provided the original work is properly cited.

\begin{abstract}
Objective: The purpose of this study was to assess whether severe overweight schizophrenic treated patients differ from controls and from pairs in binge eating symptomatology.

Method: Current body mass index (BMI) and the binge eating status were assessed crosssectionally in 40 schizophrenic outpatients and 40 non-psychiatric controls. In each group half of the subjects were severe overweight (BMI $\geq 28$ ) or obese.
\end{abstract}

Results: Pearson Chi-square analysis shows a higher number of subjects with binge symptomatology in the group of patients with schizophrenia having BMI $\geq 28$ (Pearson Chi-square $=8.67, \mathrm{p}=0.034$ ). Among subjects with $\mathrm{BMI} \geq 28,60 \%$ of patients with schizophrenia and $30 \%$ of controls have binge eating symptomatology.

Conclusion: This result may odds to the understanding of weight gain associated with antipsychotics and underscores the importance of assessing binge eating behaviour during treatment and prevention of obesity in this population.

\section{Background}

Weight gain (WG) induced by Antipsychotic drugs (AP) occurs in up to $50 \%$ of patients under chronic administration of such medication [1]. The mechanisms of AP causing WG are complex as they also involve serotoninergic, histaminergic, dopaminergic and adrenergic neurotransmissions [1]. The WG is mediated by an increase in global caloric intake, probably due to appetite and/or satiety alterations [2].

Patients frequently reported their problems associated with WG such as reduced self-esteem and repeated unsuc- cessful dietary trials $[3,4]$ as attempts to counterregulate weight gain arising during AP therapy.

Binge eating disorder (BED) is a provisional new eating disorder diagnosis [5] described in the DSM-IV research criteria. It is characterized as a pattern of recurrent episodes of binge eating in the absence of extreme weight control measures. Those episodes occur (at least twice a weekly over a 6 month period to met the diagnostic criteria as outlined in DSM-IV. This disorder have a prevalence rates of $23-55 \%$ in individuals seeking treatment for obesity compared to $2-3 \%$ in community samples $[6,7]$. 
In the obese population, binge eaters differ from non binge eaters in aspects of eating disorder psychopathology and psychiatric co-morbidity $[8,9]$. Increased perception of poor body image and lower weight self efficacy are significantly related to BED [7]. Furthermore, binge eaters tend to experience a higher level of emotional distress [10]. Those characteristics argue for an assessment of this eating disorder in patients with schizophrenia, a population more vulnerable to distress and low self esteem. A previous descriptive study found a high prevalence of BED $(12,2 \%)$ in psychotic patients treated by clozapine or olanzapine, especially in the high body mass index (BMI) subgroup [3].

The purpose of this study is to assess binge eating symptomatology in a group of individuals receiving treatment for schizophrenia and a group of non-psychiatric controls.

The groups were delineated by BMI for a comparison between individuals with high and average weight.

\section{Methods}

\section{Subjects}

The study sample consisted of 40 schizophrenic (DSM-IV) outpatients ( 19 female, mean age $33.8 \pm 9.1$ ) and 40 nonpsychiatric controls ( 21 female, mean age $35.5 \pm 10.8$ ). Both groups were each composed of two subgroups: one severely overweight subgroup (defined as a BMI > 28), and a comparison sample (BMI < 28). All patients with schizophrenia were treated by atypical AP. The WG induced by AP drugs is not necessarily associated to obesity. Due to this consideration, the threshold of BMI $=28$ was chosen.

The recruitment procedure was as follows: The study was systematically proposed during regular consultation to outpatients with schizophrenia until reaching 20 patients in each of the BMI subgroups. In total, the study was proposed to 41 outpatients over a 6 month period. Only one patient with obesity has refused to participate in the study. Controls consisted of clinic workers, informed through local advertising.
Participants gave informed consent and local Ethical Committee approval was obtained for the study.

\section{Design and measures}

The present survey was established as a cross-sectional case-control study. Subjects' BMI was calculated as weight in kilograms divided by the square of height in meters.

Binge eating status was assessed through a clinical interview, using DSM-IV criteria (SCID-IV) [11]. To be able to correctly identify binge eating episodes and frequency, detailed description of the binge eating behaviour was obtained from each subject by a senior psychiatrist or psychologist. Purging and other compensatory behaviours were also investigated. With regard to this assessment, patients and controls were classified as having (1)no bingeing, (2) binge episodes less than 2 days per week (BS), (3) BED or (4) bulimia nervosa (BN).

Psychiatric status was assessed through a chart review, medical doctor referee and psychiatrist interview.

\section{Data analyses}

Statistical analysis was performed by SPSS 12.0 program.

An initial exploratory analysis involved calculation of means and standard deviation for age, gender and BMI. Differences between the groups were tested using Kruskall-Wallis nonparametric test (for age and BMI) and chi-square tests (for gender).

Group differences in the BED and the BS prevalence were compared using the Pearson Chi-square test.

\section{Results}

The characteristics of the 4 groups are shown in Table 1 . Kruskal Wallis test revealed no differences with regard to age $(\mathrm{f}=1.2, \mathrm{df}=3, \mathrm{p}=0.16)$. No significant differences were found with regard to gender distribution $(\mathrm{Chi} 2=2.8$, $\mathrm{df}=3, \mathrm{p}=0.42$ ). As expected by the study design, Kruskal wallis non parametric test, shows a statistically significant BMI difference between groups ( $p<0.0001)$, whereas no difference was shown between high BMI schizophrenic and non schizophrenic groups ( $\mathrm{p}=0.93$ ).

Table I: Characteristics of the $\mathbf{4}$ groups $N=\mathbf{8 0}$

\begin{tabular}{|c|c|c|c|c|}
\hline & \multicolumn{2}{|c|}{ Patients with schizophrenia } & \multicolumn{2}{|c|}{ Non-psychiatric subjects } \\
\hline & BMI < 28 & $\mathrm{BMI} \geq 28$ & $\mathrm{BMI}<28$ & $\mathrm{BMI} \geq 28$ \\
\hline & $N=20$ & $N=20$ & $N=20$ & $N=20$ \\
\hline Age (mean $\pm s d)$ & $31.7 \pm 9.2$ & $36.1 \pm 8.9$ & $33.9 \pm 13.0$ & $37.2 \pm 8.1$ \\
\hline BMI (mean $\pm s d)$ & $23.6 \pm 2.2$ & $32.9 \pm 6.1$ & $21.1 \pm 2.5$ & $33.8 \pm 4.9$ \\
\hline (N. female) & 9 & 10 & 13 & 8 \\
\hline
\end{tabular}


Table 2: Binge status

\begin{tabular}{|c|c|c|c|c|c|}
\hline & \multicolumn{2}{|c|}{ Patients with schizophrenia } & \multicolumn{3}{|c|}{ Non-psychiatric subjects } \\
\hline & $\mathrm{BMI}<28$ & $\mathrm{BMI} \geq 28$ & $\mathrm{BMI}<28$ & $\mathrm{BMI} \geq 28$ & \\
\hline BED & $N=2(10 \%)$ & $N=7(35 \%)$ & $N=0(0 \%)$ & $N=2(10 \%)$ & \\
\hline BS & $N=3(15 \%)$ & $N=5(25 \%)$ & $N=4(20 \%)$ & $N=4(20 \%)$ & \\
\hline No BED nor BS Observed counts & $15 / 20(75 \%)$ & $8 / 20(40 \%)$ & $16 / 20(80 \%)$ & $14 / 20(70 \%)$ & \\
\hline BED or BS (binge symptomatology) Observed counts & $5 / 20(25 \%)$ & $12 / 20(60 \%)$ & $4 / 20(20 \%)$ & $6 / 20(30 \%)$ & Chi-square $=8,67 ; p=0.034$ \\
\hline
\end{tabular}

Binge eating status is shown in Table 2. We found that 17/ 40 of patients with schizophrenia and 10/40 of controls have binge eating symptomatology (BS or BED). Pearson Chi-square analysis shows a higher number of subjects with binge symptomatology in the group of patients with schizophrenia having $\mathrm{BMI} \geq 28$ (Pearson Chi-square = $8.67, \mathrm{p}=0.034)$. Among subjects with $\mathrm{BMI} \geq 28,60 \%$ of patients with schizophrenia and $30 \%$ of controls have binge eating symptomatology.

\section{Discussion}

The results in this study indicate that BED and BS are common behavior among overweight individuals with schizophrenia undergoing antipsychotic drug treatment. This finding confirms previous observations of high BED rates in the high BMI schizophrenic patient subgroup [12]. The principal finding of this study is the significantly higher BED and BS prevalence in the high BMI schizophrenic group than in their relative controls. This phenomenon observed in patients with schizophrenia having BMI $\geq 28$ $\mathrm{kg} / \mathrm{m} 2$, indicating that this symptomatology is not a specific correlate of antipsychotic treatment or schizophrenia but a clinical correlate of high BMI in those patients.

We can hypothesise that in certain triggered conditions (WG induced by antipsychotic drugs), patients with schizophrenia are more likely to develop BED and BS. This phenomena may be due to a higher level of emotional vulnerability, a predisposing factor to both severe overweight, BED and BS [13]. The conjunction of these factors could explain the relatively high level of binge eating symptoms observed in this study.

Due to absence of non schizophrenic psychiatric controls and the correlation nature of this study, we cannot causally link intake of antipsychotic drugs, BED, BS and WG.

Limitations of this study included the small number of controls in regard to the prevalence of BED in non overweight patients; unknown AP drugs adherence; absence of prospective design as well as absence of non schizophrenic psychiatric controls.

Nevertheless, the present results suggest that binge eating symptomatology may play an important role in the initi- ation and maintenance of the WG phenomenon observed in at least part of patients with schizophrenia. Finally, management of AP induced WG should take into account possible comorbid binge eating symptomatology leading to consider specific therapies such as cognitive and behavioural treatment adapted to those patients.

\section{References}

I. Baptista $\mathrm{T}$ : Body weight gain induced by antipsychotic drugs: mechanisms and management. Acta Psychiatr Scand 1999, 100:3-16.

2. Bromel T, Blum WF, Ziegler A, Schulz E, Bender M, Fleischhaker C, Remschmidt H, Krieg JC, Hebebrand J: Serum leptin levels increase rapidly after initiation of clozapine therapy. Mol Psychiatry 1998, 3:76-80.

3. Theisen FM, Linden A, Konig IR, Martin M, Remschmidt H, Hebebrand $\mathrm{J}$ : Spectrum of binge eating symptomatology in patients treated with clozapine and olanzapine. J Neural Transm 2003, II $0:|||-| 2 \mid$.

4. Aquila R, Emanuel M: Interventions for Weight Gain in Adults Treated With Novel Antipsychotics. Prim Care Companion J Clin Psychiatry 2000, 2:20-23.

5. Association AP: Diagnostic and statistical manual of mental disorders. 4th edition. Washington, DC, American Psychiatric Association; 1994.

6. Hsu LK, Mulliken B, McDonagh B, Krupa DS, Rand W, Fairburn CG, Rolls B, McCrory MA, Saltzman E, Shikora S, Dwyer J, Roberts S: Binge eating disorder in extreme obesity. Int J Obes Relat Metab Disord 2002, 26: I 398-1403.

7. Cargill BR, Clark MM, Pera V, Niaura RS, Abrams DB: Binge eating, body image, depression, and self-efficacy in an obese clinical population. Obes Res 1999, 7:379-386.

8. Yanovski SZ, Nelson JE, Dubbert BK, Spitzer RL: Association of binge eating disorder and psychiatric comorbidity in obese subjects. Am J Psychiatry 1993, I50:1472-1479.

9. Telch CF, Agras WS: Obesity, binge eating and psychopathology: are they related? Int J Eat Disord 1994, 15:53-61.

10. Freeman LM, Gil KM: Daily stress, coping, and dietary restraint in binge eating. Int $J$ Eat Disord 2004, 36:204-2 12.

1I. MB F, Spitzer RL, M G, J W: Structured clinical interview for DSM-IV-TR Axis I disorders- Non patient edition New York, New York State Psychiatric Institute; 200 I.

Publish with Bio Med Central and every scientist can read your work free of charge

"BioMed Central will be the most significant development for disseminating the results of biomedical research in our lifetime. "

Sir Paul Nurse, Cancer Research UK

Your research papers will be:

- available free of charge to the entire biomedical community

- peer reviewed and published immediately upon acceptance

- cited in PubMed and archived on PubMed Central

- yours - you keep the copyright

Submit your manuscript here:

http://www.biomedcentral.com/info/publishing_adv.asp
BiolMedcentral 
12. Ramacciotti CE, Paoli RA, Catena M, Ciapparelli A, Dell'Osso L, Schulte F, Garfinkel PE: Schizophrenia and binge-eating disorders. J Clin Psychiatry 2004, 65:1016-1017.

13. Womble LG, Williamson DA, Martin CK, Zucker NL, Thaw IM, Netemeyer R, Lovejoy JC, Greenway FL: Psychosocial variables associated with binge eating in obese males and females. Int J Eat Disord 200I, 30:217-22I.

Publish with Bio Med Central and every scientist can read your work free of charge

"BioMed Central will be the most significant development for disseminating the results of biomedical research in our lifetime. " Sir Paul Nurse, Cancer Research UK

Your research papers will be:

- available free of charge to the entire biomedical community

- peer reviewed and published immediately upon acceptance

- cited in PubMed and archived on PubMed Central

- yours - you keep the copyright

Submit your manuscript here:

http://www.biomedcentral.com/info/publishing_adv.asp 